\title{
Patente de invención, procedimientos para inscribir una patente en Costa Rica
}

\author{
Patent of invention, procedures for \\ registering a patent in Costa Rica
}

\section{Arys Carrasquilla-Batista ${ }^{1}$, Alfonso Chacón-Rodríguez ${ }^{2}$}

Carrasquilla-Batista, A; Chacón-Rodríguez, A. Patente de invención, procedimientos para inscribir una patente en Costa Rica. Tecnología en Marcha. Vol. 32, Especial. VIII Encuentro de Investigación y Extensión. Abril 2019. Pág 43-54.

DOI: https://doi.org/10.18845/tm.v32i6.4227

1 Ingeniera en Electrónica y Máster en Computación con énfasis en Telemática. Ingeniería Mecatrónica. Instituto Tecnológico de Costa Rica. Costa Rica. Correo electrónico: acarrasquilla@tec.ac.cr

2 Ingeniero Electrónico, Máster en Literatura Inglesa y Doctor en Ingeniería. Ingeniería Electrónica. Instituto Tecnológico de Costa Rica. Costa Rica. Correo electrónico: alchacon@tec.ac.cr 


\title{
Palabras claves
}

Ley de Patentes; Patente; Propiedad Industrial; Propiedad Intelectual; Registro Nacional.

\section{Resumen}

Este artículo tiene como objetivo principal ser un instrumento de referencia para las personas interesadas en conocer los requisitos y procedimientos, establecidos en la legislación mundial y costarricense, para la inscripción de una patente de invención. Se dan a conocer las definiciones más importantes, así como las leyes que delimitan los criterios de patentabilidad y documentos técnicos que deben presentados. Una conclusión relevante del estudio es que en Costa Rica existe toda la normativa jurídica necesaria para poder inscribir con éxito una patente. Además, se recomienda el asesoramiento por medio de expertos para que el proceso culmine con un resolución positiva, de manera tal que la Oficina de Patentes del Registro Nacional elabore la resolución de inscripción concediendo un número de patente, se emita un aviso de inscripción y se confeccione un certificado.

\begin{abstract}
The main objective of this article is to be a reference tool for people interested in knowing the requirements and procedures established in the world and Costa Rican legislation for the registration of a patent of invention. The most important definitions are disclosed, as well as the laws that define the patentability criteria and technical documents that must be presented. A relevant conclusion of the study is that in Costa Rica there are all the legal regulations necessary to be able to successfully register a patent. In addition, expert advice is recommended so that the process ends with a positive resolution, so that the Patent Office of the National Registry draws up the registration resolution granting a patent number, a registration notice and also a certificate is issued.
\end{abstract}

\section{Keywords}

Industrial Property; Intellectual Property; National Registry; Patents Law; Patent.

\section{Introducción}

Durante el primer semestre del 2015, dio inicio el Programa de Doctorado Académica en Ingeniería (PDAI) el cual es el primer doctorado interuniversitario en ingeniería de Costa Rica, las instituciones involucradas son: la Universidad de Costa Rica (UCR) y el Instituto Tecnológico de Costa Rica (ITCR). En el documento denominado "Regulaciones del programa interuniversitario de Doctorado en Ingeniería" se han establecido las definiciones y artículos que enmarcan todo el proceso, desde los mecanismos de ingreso hasta los requisitos académicos de graduación que se detallan a continuación: (1) aprobación de la malla curricular incluyendo una tesis,(2) un examen doctoral y (3) la aceptación para publicar al menos tres artículos científicos o en su defecto una patente comprobada por indicadores específicos, los cuales serán establecidos por el Consejo Consultivo. El Consejo Consultivo es el máximo órgano académico del PDAI formado por representantes de los Consejos de Unidad Responsables [1]. 
Dado que una de las posibles opciones de salida del PDAl es una patente, el presente artículo explora específicamente los requisitos y procedimientos de inscripción de una patente de invención en Costa Rica. Para el logro de este objetivo se ha organizado el documento de la siguiente manera, en el marco conceptual se define de manera general ¿qué es propiedad intelectual?, sus categorías, entes que lo regulan y sus diferentes aristas hasta llegar a las patentes. Posteriormente, se presentan las definiciones relacionadas con patentes e invenciones, que elementos no son susceptibles de patentar, requisitos de patentabilidad, y la estructura del documento técnico que debe ser presentado para optar por una patente. Por último, los requisitos para inscribir una patente en Costa Rica son explicados y se detallan las conclusiones y recomendaciones.

\section{Propiedad intelectual - marco conceptual}

\section{Propiedad Intelectual (P.I.)}

La propiedad intelectual se refiere a las creaciones de la mente: invenciones, obras literarias y artísticas, así como símbolos, nombres e imágenes utilizadas en el comercio. En el Reglamento para protección de la P.I: del ITCR [2] es definida como el "conjunto de doctrinas y normas que regulan lo referente a la apropiación e interrelación de los bienes jurídicos inmateriales que se deriven del intelecto". Es el término genérico que encierra en principio las patentes, los derechos de autor, las marcas, la información no divulgada, las indicaciones geográficas y la competencia desleal.

P.I. es un concepto en el que interviene la creatividad, la originalidad y el sello personal de cada creador; se ha establecido un mecanismo regulatorio internacional como un medio de protección para los inventores de manera tal que exista un marco jurídico que ampare los derechos de explotación de sus invenciones.

Organización Mundial de Propiedad Intelectual (OMPI)

Creada en 1967 y establecida en 1970, la Organización Mundial de la Propiedad Intelectual (OMPI), con sede en Ginebra, Suiza, es un ente internacional cuyo objetivo primordial es velar por la protección de los derechos de los creadores y todas aquellas personas físicas o jurídicas titulares de propiedad intelectual a nivel mundial y, por consiguiente, contribuir a que se reconozca y se recompense el ingenio de los inventores, autores y artistas [3].

En el año 1974 pasó a ser un organismo especializado de la Organización de las Naciones Unidas (ONU) la cual trabaja estrechamente con sus Estados miembros y demás sectores interesados; esto con el fin de asegurar la protección internacional y de esta forma estimular la creatividad humana, ensanchando las fronteras de la ciencia, tecnología, literatura y las artes. En pocas palabras, la OMPI se enfoca en crear un marco estable para la comercialización de los productos de la propiedad intelectual y facilitar el comercio internacional. Además, es el responsable de promover la protección de la Propiedad Intelectual en el mundo.

Actualmente, la OMPI cuenta con 188 Estados miembros, es decir, más del 95\% del total de países del mundo pertenecen a esta organización.

Propiedad Intelectual en Costa Rica

Costa Rica está adscrita a la OMPI desde el año 1981, la institución responsable del tema de P.I. es el Registro Nacional, ya que es el único ente gubernamental autorizado para inscribir, proteger y divulgar acciones en materia de Propiedad Intelectual. 
En Costa Rica, al igual que a nivel mundial, el tema de P.I. ha sido dividido en dos grandes ramas: propiedad industrial y derechos de autor. En la figura 1 se evidencian dichas áreas.

\section{La propiedad intelectual se divide en dos áreas}

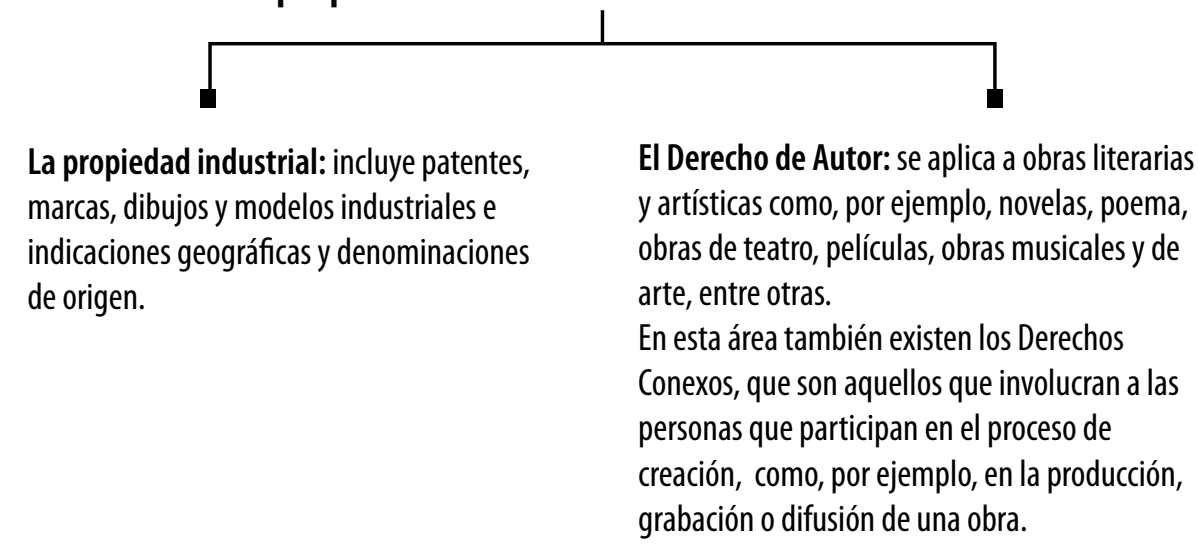

Figura 1. División en áreas de la Propiedad Intelectual [4].

En el Registro Nacional se han creado dos áreas de trabajo especializadas: [4]

\section{Registro de Derechos de Autor y Conexos}

Dentro de los objetivos de este departamento se encuentra la inscripción de las obras literarias y artísticas, actos y contratos relacionados con el derecho de autor y los derechos conexos, así como la divulgación del Derecho de Autor y los Derechos Conexos.

\section{Registro de Propiedad Industrial}

En este departamento se llevan a cabo las inscripciones relacionadas con marcas de ganado, patentes de invención, dibujos, modelos industriales, modelos de utilidad, nombres comerciales, marcas comerciales, expresiones o señales de publicidad comerciales y otros signos distintivos.

Tomando en consideración que el tema a desarrollar en la presente investigación son las patentes de invención en Costa Rica, se procede a mencionar las leyes nacionales que regulan el quehacer de la Propiedad Intelectual:

Ley de Patentes de Invención, Dibujos y Modelos Industriales y Modelos de Utilidad, número 6867 del 05 de abril de 1983.

Ley de Marcas y Otros Signos Distintivos número 7978, del $1^{\circ}$ de febrero del 2000.

El Registro de la Propiedad Industrial es la administración nacional competente adscrita al Registro Nacional, para la concesión y el registro de los derechos de propiedad industrial (patentes, diseños industriales, modelos de utilidad, marcas industriales y otros signos distintivos). Actualmente está compuesto por: la Oficina de Marcas Industriales, Oficina de Patentes de Invención, Modelos Industriales y de Utilidad y la Oficina de Marcas de Ganado.[5]

A nivel mundial la OMPI administra acuerdos internacionales relacionados con la protección de la propiedad industrial. En el cuadro 1 se resumen, específicamente, los acuerdos existentes para la protección de patentes y modelos de utilidad [6]. 
Cuadro 1. Protección de la propiedad industrial: instrumentos y acuerdos internacionales administrados por la OMPI

\begin{tabular}{|c|c|c|}
\hline \multicolumn{3}{|c|}{ Protección de la propiedad industrial } \\
\hline $\begin{array}{l}\text { Instrumentos de } \\
\text { protección }\end{array}$ & $\begin{array}{l}\text { Lo que } \\
\text { protegen }\end{array}$ & Acuerdos internacionales \\
\hline $\begin{array}{l}\text { Patentes y } \\
\text { modelos de } \\
\text { utilidad }\end{array}$ & Invenciones & $\begin{array}{l}\text { Convenio de París para la Protección de la Propiedad Industrial } \\
\text { (1883). } \\
\text { Tratado de Cooperación en materia de Patentes (1970). } \\
\text { Tratado de Budapest sobre el Reconocimiento Internacional } \\
\text { del Depósito de Microorganismos a los fines del Procedimiento } \\
\text { en Materia de Patentes (1977). } \\
\text { Arreglo de Estrasburgo relativo a la Clasificación Internacional } \\
\text { de Patentes (1971). } \\
\text { Tratado sobre el Derecho de Patentes (2000). }\end{array}$ \\
\hline
\end{tabular}

\section{Definiciones y requisitos de patentabilidad}

Antes de poder establecer los requisitos y procedimientos para la inscripción de una patente de invención en Costa Rica es preciso definir algunos términos importantes como lo son: invención, patentes e invención patentable.

- Invención: toda creación del intelecto humano, capaz de ser aplicada en la industria, como puede ser un producto, una herramienta o un procedimiento de fabricación.

- Patente: constituye el título, certificado o documento oficial que emite el Estado, a través de la Oficina de Patentes, para acreditar los derechos exclusivos que corresponden al inventor, o bien, a quien ha adquirido de éste los derechos respectivos.

- Invención Patentable: producto, máquina, herramienta o procedimiento de fabricación que reúne los tres requisitos de patentabilidad, con excepción de las invenciones indicadas por la legislación nacional: novedad, nivel inventivo y aplicabilidad industrial.

- La legislación costarricense establece además aquello que no se considera una invención (Art. 1.2 Ley), así como lo que se excluye de patentabilidad (Art. 1.4 Ley).

\section{No son consideradas invenciones}

En el documento "Información de patentes de invención, modelos de utilidad y diseño industrial" [7], elaborado por el Registro Nacional, se detallan aquellas invenciones que no son consideradas invenciones por la legislación costarricense (Art. 1.2 Ley):

- Los descubrimientos, ya que no son producto de la actividad innovadora del hombre; por ejemplo: el diamante tal y como se le conoce en la naturaleza.

- Las teorías científicas, ya que son principios puramente abstractos que no representan una contribución técnica; por ejemplo: la teoría de la Evolución de las Especies de Charles Darwin.

- Los métodos matemáticos, ya que son principios puramente abstractos que no representan una contribución técnica; por ejemplo: el Teorema de Pitágoras.

- Los programas de ordenador (software) ya que es materia de derechos de autor. 
- Las creaciones puramente estéticas, las obras literarias y artísticas ya que se protegen por derechos de autor; por ejemplo las obras escritas por Carmen Lyra.

- Los planes, principios o métodos económicos de publicidad o de negocios y los referidos a actividades puramente mentales, intelectuales o a materia de juego; como por ejemplo el juego de ajedrez o el método para resolver crucigramas.

- La yuxtaposición de invenciones conocidas o mezclas de productos conocidos, su variación de forma o uso, dimensiones o materiales; como por ejemplo las recetas de cocina.

P.I. es un concepto en el que interviene la creatividad, la originalidad y el sello personal de cada creador; se ha establecido un mecanismo regulatorio internacional como un medio de protección para los inventores de manera tal que exista un marco jurídico que ampare los derechos de explotación de sus invenciones.

Que se excluye de la patentabilidad

En la legislación costarricense, específicamente el artículo 1.4 de la Ley 6867, se detalla lo que se excluye de patentabilidad [8]:

- Las invenciones cuya explotación comercial deba impedirse objetiva y necesariamente para proteger el orden público, la moralidad, la salud o la vida de las personas o los animales o para preservar los vegetales o evitar daños graves al ambiente.

- Los métodos de diagnóstico, terapéuticos y quirúrgicos para el tratamiento de personas o animales.

- Las plantas y los animales.

- Los procedimientos esencialmente biológicos para la producción de plantas o animales. Así reformado por el artículo 2.a) de la Ley 7979 del 6 de enero del 2000.

\section{Requisitos de Patentabilidad}

En el artículo 2 de la Ley se establecen los requisitos que debe reunir una invención para que pueda ser protegida mediante una patente:

- Novedad: la invención debe ser nueva; es decir, que no exista en el estado de la técnica antes de la fecha de la solicitud.

El estado de la técnica comprende todo lo divulgado o hecho accesible al público en cualquier lugar del mundo y por cualquier medio antes de la fecha de presentación en Costa Rica o de la fecha de prioridad aplicable.

Es importante destacar que el concepto de novedad es absoluto; es decir, que la invención deberá ser nueva a nivel mundial y no solo en el país donde se solicita la patente.

- Nivel Inventivo: una invención tendrá nivel inventivo si para una persona de nivel medio, entendida en el campo técnico de la invención, esa invención no hubiese resultado obvia ni evidente, tomando en cuenta el estado de la técnica conocido.

- Aplicación Industrial: la invención debe tener una utilidad específica, sustancial y creíble. 
- La aplicación industrial no implica que deba garantizarse que la invención en cuestión haya sido efectivamente producida o utilizada de manera industrial. Basta que con la descripción de la invención se deduzca que pueda serlo.

\section{Documento técnico de una patente}

El documento técnico de una patente está conformado por Descripción o Memoria Descriptiva, Reivindicaciones y Resumen.

Descripción (Art. 6.4 Ley, Art. 7 Reglamento). La descripción de la invención cumple la función importante de divulgar la invención. Ello significa que la invención debe estar descrita en una forma suficientemente clara y completa para que sea posible su comprensión y para que una persona capacitada en la materia técnica correspondiente pueda ponerla en práctica.

Características de la Descripción:

- Suficiencia: La descripción debe contener la suficiente información técnica para que una persona con conocimiento medio en el arte pueda poner en práctica la invención. Esta divulgación debe ser suficiente para conocer el aporte que se está haciendo a la tecnología.

- Claridad: La divulgación de la invención debe realizarse en términos que permitan la comprensión del problema técnico y la solución aportada por la invención. Se pueden exponer asimismo las ventajas que se tienen con respecto al estado de la técnica. Es responsabilidad del solicitante suministrar la información en la descripción de forma clara.

Reivindicaciones (Art. 6.5 Ley, Art. 8 y 9 Reglamento). Las reivindicaciones establecen la materia que se desea proteger mediante la patente. Deben ser claras y concisas y estar enteramente sustentadas por la descripción, ya que estas definen la invención que debe ser protegida y delimitan el alcance de esa protección. Deben contener todas las características técnicas esenciales de la invención que definen la invención y la hacen, o pudieran hacerla, distintiva del estado de la técnica.

Características de las Reivindicaciones:

- Claridad: El significado y alcance de las palabras de las reivindicaciones debe ser el que normalmente se les da en el área técnica de la solicitud, y tiene que ser claro para la persona versada en la materia con la sola lectura de las reivindicaciones.

- Concisión: Se debe evitar una excesiva complejidad para el examinador a la hora de analizar las reivindicaciones, y evitar que terceros no puedan ver claramente cuál es el alcance de las reivindicaciones por el excesivo número y complejidad de éstas.

- Soporte: Las reivindicaciones tienen que estar sustentadas en la descripción. Esto significa que el objeto de cada reivindicación tiene que tener su fundamento en la descripción y que su alcance no debe exceder más allá de lo justificado por el contenido de la descripción y los dibujos.

Resumen (Art. 6.6 Ley, Art. 10 Reglamento). El resumen debe indicar el campo técnico al que pertenece la invención, lo esencial del problema técnico y de la solución aportada por la invención, así como el uso principal de esta. El resumen, servirá solo para fines de información técnica.

La forma en que deben ser presentados los "Dibujos" han sido establecidos en el Manual de organización y examen de solicitudes de patentes de invención, los dibujos, planos, figuras 
y representaciones gráficas tienen como finalidad contribuir a una mejor comprensión y divulgación de la invención.

Características de los Dibujos:

- Tener una relación directa con la descripción

- La relación entre la descripción y los dibujos se debe hacer por medio de signos de referencia que se encuentren en ambos elementos y guarden una correspondencia.

- Si en la descripción se mencionan figuras, estas deben, obligatoriamente, estar incluidas.

- En lo posible, no deben incluirse textos o letreros.

- Deben ser numerados individual y consecutivamente.

En la figura 2 se muestra la estructura general del documento técnico de una patente de invención.

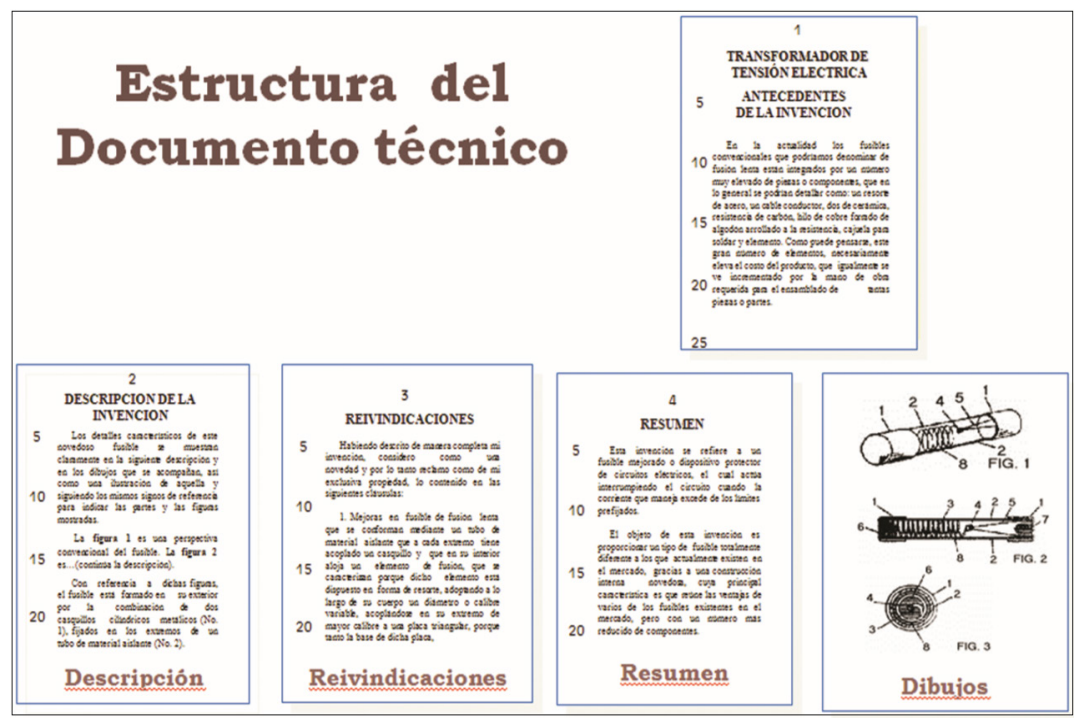

Figura 2. Estructura del documento técnico para la presentación de una patente de invención [7]

\section{Procedimientos para la inscripción de una patente}

Dentro de los procedimientos que han sido establecidos para la inscripción de una patente de invención, se deben considerar los siguientes pasos o requisitos:

Requisitos de forma

A continuación se detallan todos los requisitos que deben ser cumplidos en el proceso:

Entregar el "Formulario de solicitud" en cual está disponible en [9] y debe contener:

- Nombre y calidades del titular, inventor o creador y del representante

- Título de la invención 
- Sector tecnológico

- Lugar o medio para atender notificaciones

- Firma del inventor o solicitante autenticada (Timbre)

- Timbre de $ф 20$ de Archivo Nacional

- Descripción de la invención, Reivindicaciones y Resumen

- Dibujos, cinco (5) representaciones gráficas, diferentes ángulos

- Mandato (si se requiere) Art. 34 y 34bis Ley y 6 Reglamento, el Reglamento está disponible en [10].

- Documento idóneo para corroborar titularidad (cesión de derechos) Art. 6.3 Ley y 5.5 Reglamento.

\section{Publicación de la solicitud}

Una vez cumplidos todos los requisitos formales, se emite un aviso que se le entrega al solicitante para su publicación. Debe ser publicado por tres veces consecutivas en el diario oficial La Gaceta y una vez en un diario de circulación nacional, esto para efectos de mantenerse los tiempos que permitan recibir oposiciones dentro del término de ley.

El solicitante debe aportar dentro del mes siguiente al retiro del aviso, los comprobantes de pago de las publicaciones antes indicadas.

\section{Oposiciones}

Cualquiera que considere que no debe concederse una patente, porque la solicitud no cumple los requisitos de novedad, nivel inventivo y aplicación industrial, puede interponer oposición en el plazo de tres meses, contados a partir de la tercera publicación de la solicitud en el diario oficial La Gaceta.

La oposición deberá estar debidamente fundamentada, acompañada de las pruebas pertinentes y del comprobante de pago de la tasa establecida para las oposiciones.

\section{Examen de fondo}

El examinador analizará si la invención es patentable y determinará si la solicitud presentada es considerada una invención o si la materia que se pretende proteger se encuentra dentro de las exclusiones de patentabilidad. Además, evaluará el cumplimiento de los requisitos de novedad, nivel inventivo y aplicación industrial, así como si la solicitud satisface el requisito de unidad de la invención; es decir, que la solicitud incluya solo un objeto inventivo.

El evaluador también examinará si la solicitud presentada tiene correspondencia con la prioridad invocada, es decir, si la descripción cumple con las características de suficiencia y claridad y si las reivindicaciones son claras, concisas y están soportadas en la descripción. Al finalizar, el examinador emitirá un informe técnico que puede dar lugar a la inscripción parcial o total de la Patente de Invención, lo cual dependerá de las reivindicaciones aprobadas; o bien, a la denegatoria de la solicitud presentada.

\section{Costos relacionados con la inscripción de una patente de invención}

Tasa de presentación

Toda trámite de solicitud de patentes deberá realizar el pago de quinientos dólares americanos US $\$ 500$, pagaderos en colones al tipo del cambio del día, excepto en el caso de personas 
físicas, micro o pequeñas empresas, instituciones de Educación Superior Públicas o institutos de investigación científica y tecnológica del Sector Público, cuya tasa es por la suma de ciento cincuenta dólares americanos (US\$150).

Estudio de fondo o examen de fondo

El monto a pagar por parte del solicitante para que se realice el estudio de fondo de su solicitud es la suma de US\$525,00.

Otras tasas

- Cada solicitud fraccionaria: US\$500,00.

- Inscripción y expedición del certificado de registro de la patente: US\$500,00.

- Solicitud de extensión de la vigencia del plazo de la patente: US\$150,00.

- Tasas anuales: US\$500,00.

- Oposición: US\$25.

- Sobretasa por pago dentro del período de gracia: treinta por ciento (30\%) de la tasa anual correspondiente.

\section{Procedimiento de concesión o denegación}

En caso de que en el estudio de fondo el examinador emita un informe técnico positivo, en el que se aprueban la totalidad de las reivindicaciones, la Oficina de Patentes elabora la resolución de inscripción concediendo un número de patente, se emite un aviso de inscripción y se confecciona un certificado.

Si se trata de un informe técnico negativo, porque se aprueban solo algunas reivindicaciones o se rechazan todas, se emite una resolución que se notifica al titular de la solicitud otorgándole el plazo de 1 mes para que presente sus aclaraciones al respecto. Estas manifestaciones se remiten nuevamente al examinador para que emita el informe técnico concluyente, el cual será el fundamento técnico para la elaboración de la resolución de inscripción o de la resolución de denegatoria, la cual generará el archivo de la solicitud.

\section{Plazo de vigencia de la patente}

La patente tendrá una vigencia de veinte (20) años improrrogables, contados a partir de la fecha de presentación de la solicitud en el Registro de la Propiedad Industrial o, para el caso de patentes tramitadas bajo el Tratado de Cooperación en Materia de patentes, desde la fecha de la presentación internacional.

La protección que otorga la patente de invención es territorial; es decir, si la solicitud se presenta en Costa Rica, solo queda protegida en Costa Rica. Expirado el plazo de protección, la invención pasa a pertenecer al dominio público, quedando disponible para la explotación comercial por parte de terceros.

\section{Derecho del titular}

La patente confiere al titular el derecho a explotar, en forma exclusiva, la invención y conceder licencias a terceros para la explotación. Asimismo, la patente conferirá a su titular los siguientes derechos exclusivos: 
- Si se trata de un producto, el de impedir que terceros, sin su consentimiento, realicen actos de fabricación, uso, oferta para la venta, venta o importación del producto objeto de la patente.

- Si es un procedimiento, el de impedir que terceros, sin su consentimiento, utilicen el procedimiento o el producto obtenido directamente mediante dicho procedimiento, así como la oferta para la venta, venta o importación de dicho producto.

\section{Conclusiones y recomendaciones}

A nivel mundial existe un marco jurídico regulatorio, establecido por la OMPI, que ha establecido las definiciones, requisitos y procedimientos relacionados con la inscripción de la Propiedad Intelectual y sus dos categorías: Propiedad Industrial la cual abarca las patentes de invención y Derechos de Autor y Conexos.

En Costa Rica, el Registro Nacional es el único ente gubernamental autorizado para inscribir, proteger y divulgar acciones en materia de Propiedad Intelectual.

En el Registro Nacional existe el Centro de Apoyo a la Tecnología y la Innovación (CATI), ubicado en el Registro de Propiedad Industrial, en este centro se ofrece al inventor la información y el apoyo necesario, para realizar la búsqueda de antecedentes para tramitar la inscripción de una invención. Se recomienda a los interesados hacer uso de dicho centro.

También se recomienda a los inventores que recurran a las instancias universitarias destinadas a la Propiedad Intelectual, en el caso del ITCR se ha asignado el Centro de Vinculación Universidad Empresa, departamento adscrito a la Vicerrectoría de Investigación y Extensión (VIE) para que se involucren e instruyan a los investigadores en esta temática.

Al realizar la búsqueda se puede hacer por distintas vías, como por ejemplo: nombre del inventor, nombre del solicitante, palabra del título o del resumen de la invención, clasificación internacional de patentes, entre otras.

Son muchas las bases de datos existentes para la búsqueda de información relacionada con patentes, se sugiere iniciar con las más importantes:

- Oficina Española de Patentes y Marcas: http://www.oepm.es

- Oficina Europea de Patentes: http://ep.espacenet.com

- Oficina de Patentes y Marcas de los Estados Unidos: http://www.uspto.gov

\section{Referencias}

[1] ITCR, UCR, "Regulaciones del programa interuniversitario de Doctorado en Ingeniería" junio 2015. Disponible en:. http://www.tec.ac.cr/posgrados/doctoradoingenieria/Documents/Regulaciones\%20del\%20programa\%20 interuniversitario\%20de\%20Doctorado\%20en\%20Ingenier\%C3\%ADa\%20_Junio\%202015.pdf

[2] ITCR. "Reglamento para la protección de la Propiedad del Instituto Tecnológico de Costa Rica, (s.f), Disponible en: http://www.itcr.ac.cr/reglamentos/Consultas/consultarR1.asp?n=279

[3] OMPI. "Principios Básicos de la Propiedad Industrial", Publicación de la OMPI No. 895(S) ISBN 978-92-8051615-9, (s.f). Disponible en: http://www.wipo.int/edocs/pubdocs/es/intproperty/895/wipo_pub_895.pdf

[4] Registro Nacional de la República de Costa Rica, "Conozcamos sobre Propiedad Intelectual", suplemento publicitario comercial. octubre 2013. 
[5] Registro Nacional de Costa Rica, "Historia de propiedad Industrial en Costa Rica, (s.f). Disponible en: http:// www.registronacional.go.cr/propiedad_industrial/propiedad_industrial_historia.htm

[6] OMPI, Publicación de la OMPI No 895(S) ISBN 978-92-805-1615-9, página 22. (s.f).

[7] Registro Nacional de Costa Rica "Información de patentes de invención, modelos de utilidad y diseño industrial"(s.f.) Disponible en : http://www.rnpdigital.com/.

[8] Asamblea Legislativa de la República de Costa Rica "Ley de Patentes de Invención, Dibujos y Modelos de Industriales y Modelos de Utilidad No. 6867". Modificada en octubre del 2000. Disponible en: http://www.wipo. int/edocs/lexdocs/laws/es/cr/cr002es.pdf.

[9] Registro de la Propiedad Industrial, Registro Nacional de Costa Rica "Solicitud de Inscripción de Patente de Invención, Modelo de Utilidad o Diseño Industrial” Disponible en: http://www.rnpdigital.com/propiedad_industrial/documentos/pi_servicios_formularios/formularios/RPI-10\%20Formulario\%20de\%20Solicitud.pdf

[10] Presidencia de la República de Costa Rica y los Ministerios de Industria, Energía y Minas y de Justicia y Gracia. "Reglamento de la Ley de patentes de Invención. Dibujos y Modelos Industriales y Modelos de Utilidad (Decreto No. 15222- MIEM-J). Disponible en: http://www.wipo.int/wipolex/en/text.jsp?file_id=221252 